\title{
The anterior cingulate cortex: an integrative hub for human socially-driven interactions
}

\author{
Claudio Lavin ${ }^{1,2,3}$, Camilo Melis ${ }^{3}$, Ezequiel Mikulan ${ }^{4}$, Carlos Gelormini ${ }^{4}$, David Huepe $^{2}$ and \\ Agustin Ibañez ${ }^{2,4}$ * \\ ${ }^{1}$ Center of Argumentation and Reasoning Studies, Universidad Diego Portales, Santiago, Chile \\ 2 Laboratory of cognitive and social neuroscience, Universidad Diego Portales, Santiago, Chile \\ ${ }^{3}$ Facultad de Economía y Empresa, Centro de Neuroeconomía, Universidad Diego Portales, Santiago, Chile \\ ${ }^{4}$ Laboratory of Experimental Psychology and Neuroscience, Institute of Cognitive Neurology (INECO), Favaloro University, Buenos Aires, Argentina \\ ${ }^{*}$ Correspondence: aibanez@ineco.org.ar
}

\section{Edited by:}

Steve W. Chang, Duke University, USA

Masaki Isoda, Kansai Medical University, Japan

Reviewed by:

Steve W. Chang, Duke University, USA

The activity of the anterior cingulate cortex (ACC) has been related to decisionmaking (Gehring and Willoughby, 2002; Sanfey et al., 2003; Mulert et al., 2008), socially-driven interactions (Sanfey et al., 2003; Rigoni et al., 2010; Etkin et al., 2011), and empathy-related responses (van Veen and Carter, 2002; Gu et al., 2010; Lamm et al., 2011). We present a perspective of how to interpret the evidence of ACC involvement in these three processes, propose an ACC integrative function, and provide a methodological pathway to study decision making, empathy, and social interaction in a combined experimental approach.

Error detection and outcome monitoring are two important decision processes related to ACC activation (Bush et al., 2000; Gehring and Willoughby, 2002; Hewig et al., 2011). Although the ACC was previously associated with basic error detection processes (Carter et al., 1998; van Veen et al., 2001), evidence from electroencephalographic (EEG) and functional magnetic resonance imaging (fMRI) during the last decade has suggested the involvement of the ACC in high-level processing (in outcome/error monitoring and action planning; Bush et al., 2000). The error-related negativity (ERN) and feedback-related negativity (FRN), two event-related potentials (ERP) that consistently follow action errors and negative outcomes, respectively (e.g., San Martin et al., 2010), are associated with activity in the ACC. The evidence of the ACC involvement in the ERN and FRN is consistent across different types of studies. In patients with ACC lesions, for instance, a robust affectation of ERN has been found (Stemmer et al., 2004; Hogan et al., 2006). Intracranial measurements confirmed ACC involvement in ERN (Brazdil et al., 2005; Jung et al., 2010), and the same evidence has been found with source localization (Dehaene et al., 1994; Holroyd et al., 1998; van Veen and Carter, 2002; Donamayor et al., 2011; Bediou et al., 2012; Ibáñez et al., 2012) and magneto-encephalography (Miltner et al., 2003). These findings are supported by fMRI studies that indicate the activation of the dorsal and rostral areas of the ACC when subjects receive feedback after losses associated with errors in decisionmaking tasks (Bush et al., 2002; Marsh et al., 2007). There is also animal evidence that shows specific anterior cingulate sulcus activation with respect to one's foregone rewards, and of the anterior cingulate gyrus (ACCg) with respect to self, others' or both players' rewards (Chang et al., 2013). This evidence shows that the ACC is a part of the decision-making network that involves activity in prefrontal and parietal areas related to the observation of alternatives (Platt and Glimcher, 1999; Westendorff et al., 2010), and activity in the orbitofrontal (OFC) and ventromedial prefrontal cortex related to the representation of option values (Buckley et al., 2009; Mullette-Gillman et al., 2011). There is also evidence of connections of the ACC to the insula, related to interoceptive markers of negative emotions (Ibanez et al., 2010b; Jones et al., 2011; Kunz et al., 2011; Couto et al., 2013). In addition, there is evidence that central-rostral areas of the ACC are connected to the limbic system
(Etkin et al., 2011). The ACC receives inputs from these structures relative to the differences between expected and actual outcomes of a given decision, and provides outputs to coordinate dorsolateral prefrontal structures in order to organize behavioral responses (Cohen et al., 2005; Mansouri et al., 2009; Shackman et al., 2011; see Figure 1).

Furthermore, several studies show ACC activation indexing empathy-related response in pain/no-pain paradigms. The ACC is a core component of the pain network which is active when subjects receive pain stimuli and can also be activated when observing others in such situations (see Figure 1). This pain network involves activity in the bilateral anterior insula (AI), rostral ACC, brainstem, and cerebellum when observing a loved one experiencing pain, and activity in the posterior insular/secondary somatosensory cortex, the sensorimotor cortex (SI/MI), and caudal ACC when experiencing pain (Singer et al., 2004, 2006; Jackson et al., 2005, 2006; Decety and Jackson, 2006; Lamm et al., 2011). Moreover, the activation of the ACC in observational-pain paradigms is modulated by contextual information about the one observed. For instance, observing a prosocial subject receiving pain stimulation triggers empathy responses reflected in increased bilateral activity of the AI and the ACC, compared to observing an antisocial subject (Singer et al., 2006). This evidence suggests the involvement of the ACC in high-level cognitive processing when observing others and its modulation by critical contextual cues. 


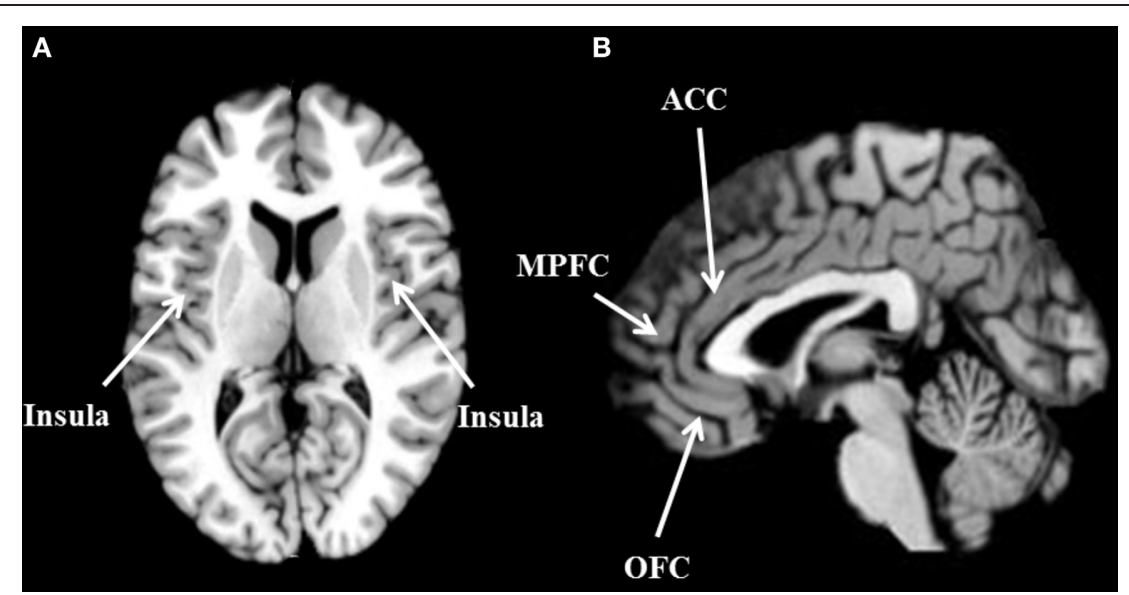

FIGURE 1 | Brain areas commonly active during empathy-related responses and decision making tasks. (A) Axial view of the bilateral insula. (B) Sagittal view of the anterior cingulate cortex (ACC), medial prefrontal cortex (MPFC), and orbitofrontal cortex (OFC).

This high-level contextual processing of the ACC has also been studied regarding socio-affective variables within traditional decision-making paradigms. ACC is active when people observe others' action errors, but this activation is modulated by group membership of social stimuli (NewmanNorlund et al., 2009; Hein et al., 2010). ERP studies have also provided evidence in this line, showing FRN modulation associated with (1) unfairness considerations in socio-economical interactions (Boksem and De Cremer, 2010), (2) observing a friend or a stranger playing a gambling task (Ma et al., 2011), and also (3) offers made by a computer program vs. humans in ultimatum games (UG) (Fukushima and Hiraki, 2009). These neuroimaging and electrophysiological experiments suggest that ACC integrates high level information for making decisions that involve economic and social concerns. The processing in the ACC is not just related to the economic value of a given outcome, but also to the social aspects involved in the interaction. For example, the ACC activity would be differentially modulated if people, in an UG, are willing to accept unfair offers made by a computer program or by a real player (Fukushima and Hiraki, 2009). Even though the payoffs are the same, considerations about fairness/unfairness are attached to the economic interactions reflecting activity of empathy networks, theory of mind (ToM) and decision-making (Etkin et al., 2011). Although this is not conclusive of the inte- grative role of the ACC, the specificity of the ACC activation in decision-making paradigms when there are contextual cues, together with the role of the ACC in empathy-related responses without outcome feedback give support to this interpretation.

There is consistent evidence of the active role that the ACC plays in the processing of multimodal of contextdependent events, compared to noncontextual stimuli (Downar et al., 2001, 2002). This evidence is in line with the idea that social cognition involves the integration of flexible and contextdependent information (Chang et al., 2011; Ibanez and Manes, 2012). Taken together, these data suggest that the ACC might be a center of integration of information about others' social background that has a direct effect on economic interactions. Thus, interacting with someone from an out-group is different than interacting with someone from an ingroup (Ibanez et al., 2010a) not just from a social perspective, but also in terms of how we process the economic payoffs extracted by such interactions regarding our own and others' welfare. This involves self-concern aspects of outcome processing, and empathy responses modulated by social information about others. Although we know all these processes occur to some extent in the ACC, it remains unclear which specific social cues modulate empathy in each group, and the degree to which empathy-related responses modulate cooperative behavior, outcome processing, and decisionmaking. In brief, most of the evidence provided focuses on just one variable (e.g., outcome monitoring or empathy) and there is no theoretical approach that has been able to integrate all variables together. Furthermore, ERP studies on the contextual cues involved in error or outcome processing tend to associate unpleasant social contexts with negative economic feedback (Boksem and De Cremer, 2010). For this reason, it is hard to evaluate the influence of contextual social cues on the processes of decision-making. Also, traditional fMRI studies, which focused on empathy, tended to put aside variables associated with outcome processing.

A further approach for studying the role of the ACC in the integration of social information, empathy and decisionmaking, should involve the confrontation of these factors in a single paradigm. This would allow us to observe the influence of contextual information on empathy responses, and, in turn, to evaluate whether these responses modulate the monitoring of wins and losses. For instance, fairness/unfairness considerations about others' behavior may trigger different levels of empathy-related responses depending on whether the observer profits from such behavior or not. Thus, if a given subject profits from someone else's unfair behavior, ACC activity might be affected by the economic benefit of such unfair behavior. This experimental model could explore ACC activity within conflicting situations between negative emotional states (e.g., feeling bad for observing someone being exploited or committing an error), and the positive evaluation of outcomes derived from such situations. This could show overlapping activity in the ACC, or the activation of specific areas associated with error detection, outcome processing and empathy-related responses. The same might happen when disentangling action errors from negative outcomes, as some ERP studies are doing (de Bruijn and von Rhein, 2012), where negativity associated with error detection exists even if the outcomes are positive. Such conflicts are common in real-life situations and exploring them seems essential for understanding and predicting actions 
within interactions under particular social settings.

The evidence summarized here supports the idea of the ACC as a center of high level contextual integration and behavior monitoring. We believe that a consistent and testable model of differential empathy-related responses using critical contextual cues (such as perceived fairness/unfairness or group identity) within a decision-making setting could provide important insights about partially overlapping ACC networks of these three cognitive domains. Real-life decision making is full of contextual cues that involve conflict between two or more alternatives at the same time (Baez et al., 2012, 2013; Ibanez and Manes, 2012). People might feel empathy for a fair player's loss but at the same time they might want to get benefits from a zero sum interaction, so there is a decision to be made in terms of which strategy weighs more in the final output. In this context, the role of the ACC would be essential for understanding how contextual information shapes our strategic decisions, and how this influences the way in which we learn from others and evaluate them in social terms.

\section{ACKNOWLEDGMENTS}

This work was supported by grants FONDECYT (1130920), CONICET (Carlos Gelormini, Agustin Ibañez) and INECO Foundation.

\section{REFERENCES}

Baez, S., Herrera, E., Villarin, L., Theil, D., GonzalezGadea, M. L., Gomez, P., et al. (2013). Contextual social cognition impairments in schizophrenia and bipolar disorder. PLOS ONE 8:e57664. doi: 10.1371/journal.pone.0057664

Baez, S., Rattazzi, A., Gonzalez-Gadea, M. L., Torralva, T., Vigliecca, N. S., Decety, J., et al. (2012). Integrating intention and context: assessing social cognition in adults with Asperger syndrome. Front. Hum. Neurosci. 6:302. doi: 10.3389/fnhum.2012.00302

Bediou, B., Koban, L., Rosset, S., Pourtois, G., and Sander, D. (2012). Delayed monitoring of accuracy errors compared to commission errors in ACC. Neuroimage, 60, 1925-1936.

Boksem, M. A., and De Cremer, D. (2010). Fairness concerns predict medial frontal negativity amplitude in ultimatum bargaining. Soc. Neurosci. 5, $118-128$.

Brazdil, M., Dobsik, M., Mikl, M., Hlustik, P., Daniel, P., Pazourkova, M., et al. (2005). Combined eventrelated fMRI and intracerebral ERP study of an auditory oddball task. Neuroimage, 26, 285-293.
Buckley, M. J., Mansouri, F. A., Hoda, H., Mahboubi, M., Browning, P. G., Kwok, S. C., et al. (2009). Dissociable components of rule-guided behavior depend on distinct medial and prefrontal regions. Science 325, 52-58.

Bush, G., Luu, P., and Posner, M. I. (2000). Cognitive and emotional influences in anterior cingulate cortex. Trends Cogn. Sci. 4, 215-222.

Bush, G., Vogt, B. A., Holmes, J., Dale, A. M., Greve, D., Jenike, M. A., et al. (2002). Dorsal anterior cingulate cortex: a role in reward-based decision making. Proc. Natl. Acad. Sci. U.S.A. 99, 523-528.

Carter, C. S., Braver, T. S., Barch, D. M., Botvinick, M. M., Noll, D., and Cohen, J. D. (1998). Anterior cingulate cortex, error detection, and the online monitoring of performance. Science 280, 747-749.

Chang, S. W., Gariepy, J. F., and Platt, M. L. (2013). Neuronal reference frames for social decisions in primate frontal cortex. Nat. Neurosci. 16, 243-250.

Chang, S. W., Winecoff, A. A., and Platt, M. L. (2011). Vicarious reinforcement in rhesus macaques (macaca mulatta). Front. Neurosci. 5:27. doi: 10.3389/fnins.2011.00027

Cohen, M. X., Heller, A. S., and Ranganath, C. (2005). Functional connectivity with anterior cingulate and orbitofrontal cortices during decisionmaking. [Clinical Trial]. Brain Res. Cogn. Brain Res. 23, 61-70.

Couto, B., Sedeño, L., Sposato, L., Sigman, M., Riccio, P., Salles, A., et al. (2013). Insular networks for emotional processing and social cognition: comparison of two case reports with either cortical or subcortical involvement. Cortex, 5, 1420-1434.

de Bruijn, E. R. A., and von Rhein, D. T. (2012). Is your error my concern? An event-related potential study on own and observed error detection in cooperation and competition. Front. Neurosci. 6, 1-9. doi: 10.3389/fnins.2012.00008

Decety, J., and Jackson, P. L. (2006). A socialneuroscience perspective on empathy. Curr. Dir. Psychol. Sci. 15, 54-58.

Dehaene, S., Posner, M. I., and Tucker, D. M. (1994). Localization of a Neural System for Error Detection and Compensation. Psychol. Sci. 5, 303-305.

Donamayor, N., Marco-Pallares, J., Heldmann, M., Schoenfeld, M. A., and Munte, T. F. (2011). Temporal dynamics of reward processing revealed by magnetoencephalography. Hum. Brain Mapp. 32, 2228-2240.

Downar, J., Crawley, A. P., Mikulis, D. J., and Davis, K. D. (2001). The effect of task relevance on the cortical response to changes in visual and auditory stimuli: an event-related fMRI study. Neuroimage 14, 1256-1267.

Downar, J., Crawley, A. P., Mikulis, D. J., and Davis, K. D. (2002). A cortical network sensitive to stimulus salience in a neutral behavioral context across multiple sensory modalities. J. Neurophysiol. 87, 615-620.

Etkin, A., Egner, T., and Kalisch, R. (2011). Emotional processing in anterior cingulate and medial prefrontal cortex. Trends Cogn. Sci. 15, 85-93.

Fukushima, H., and Hiraki, K. (2009). Whose loss is it? Human electrophysiological correlates of nonself reward processing. Soc. Neuroci. 4, 261-275.

Gehring, W. J., and Willoughby, A. R. (2002). The medial frontal cortex and the rapid processing of monetary gains and losses. Science 295, 2279-2282.
Gu, X., Liu, X., Guise, K. G., Naidich, T. P., Hof, P. R., and Fan, J. (2010). Functional dissociation of the frontoinsular and anterior cingulate cortices in empathy for pain. J. Neurosci. 30, 3739-3744.

Hein, G., Silani, G., Preuschoff, K., Batson, C. D., and Singer, T. (2010). Neural responses to ingroup and outgroup members' suffering predict individual differences in costly helping. Neuron 68, 149-160.

Hewig, J., Kretschmer, N., Trippe, R. H., Hecht, H., Coles, M. G., Holroyd, C. B., et al. (2011). Why humans deviate from rational choice. Psychophysiology 48, 507-514.

Hogan, A. M., Vargha-Khadem, F., Saunders, D. E., Kirkham, F. J., and Baldeweg, T. (2006). Impact of frontal white matter lesions on performance monitoring: ERP evidence for cortical disconnection. Brain, 129, 2177-2188.

Holroyd, C. B., Dien, J., and Coles, M. G. (1998). Error-related scalp potentials elicited by hand and foot movements: evidence for an outputindependent error-processing system in humans. Neurosci. Lett. 242, 65-68.

Ibáñez, A., Cetkovich, M., Petroni, A., Urquina, H., Baez, S., Gonzalez, L., et al. (2012). The neural basis of decision-making and reward processing in adults with euthymic bipolar disorder or attention-deficit/hyperactivity disorder (ADHD). PLoS ONE 7:e37306. doi: 10.1371/ journal.pone.0037306.

Ibanez, A., and Manes, F. (2012). Contextual social cognition and the behavioral variant of frontotemporal dementia. Neurology 78, 1354-1362.

Ibanez, A., Gleichgerrcht, E., Hurtado, E., Gonzalez, R., Haye, A., and Manes, F. F. (2010a). Early neural markers of implicit attitudes: N170 modulated by intergroup and evaluative contexts in IAT. Front. Hum. Neurosci. 4:188. doi: 10.3389/fnhum.2010.00188

Ibanez, A., Gleichgerrcht, E., and Manes, F. (2010b). Clinical effects of insular damage in humans. Brain Struct. Funct. 214, 397-410.

Jackson, P. L., Brunet, E., Meltzoff, A. N., and Decety, J. (2006). Empathy examined through the neural mechanisms involved in imagining how I feel versus how you feel pain. Neuropsychologia, 44, 752-761.

Jackson, P. L., Meltzoff, A. N., and Decety, J. (2005). How do we perceive the pain of others? A window into the neural processes involved in empathy. Neuroimage, 24, 771-779.

Jones, C. L., Minati, L., Harrison, N. A., Ward, J., and Critchley, H. D. (2011). Under pressure: response urgency modulates striatal and insula activity during decision-making under risk. PLoS ONE 6:e20942. doi: 10.1371/journal.pone.0020942

Jung, J., Jerbi, K., Ossandon, T., Ryvlin, P., Isnard, J., Bertrand, O., et al. (2010). Brain responses to success and failure: Direct recordings from human cerebral cortex. Hum. Brain Mapp. 31, 1217-1232.

Kunz, M., Chen, J. I., Lautenbacher, S., VachonPresseau, E., and Rainville, P. (2011). Cerebral regulation of facial expressions of pain. J. Neurosci. 31, 8730-8738.

Lamm, C., Decety, J., and Singer, T. (2011). Metaanalytic evidence for common and distinct neural networks associated with directly experienced pain and empathy for pain. Neuroimage 54, 2492-2502. 
Ma, Q., Shen, Q., Xu, Q., Li, D., Shu, L., and Weber, B. (2011). Empathic responses to others' gains and losses: an electrophysiological investigation. Neuroimage, 54, 2472-2480.

Mansouri, F. A., Tanaka, K., and Buckley, M. J. (2009). Conflict-induced behavioural adjustment: a clue to the executive functions of the prefrontal cortex. Nat. Rev. Neurosci. 10, 141-152.

Marsh, A. A., Blair, K. S., Vythilingam, M., Busis, S., and Blair, R. J. (2007). Response options and expectations of reward in decision-making: the differential roles of dorsal and rostral anterior cingulate cortex. Neuroimage 35, 979-988.

Miltner, W. H., Lemke, U., Weiss, T., Holroyd, C., Scheffers, M. K., and Coles, M. G. (2003). Implementation of error-processing in the human anterior cingulate cortex: a source analysis of the magnetic equivalent of the error-related negativity. Biol. Psychol. 64, 157-166.

Mulert, C., Seifert, C., Leicht, G., Kirsch, V., Ertl, M., Karch, S., et al. (2008). Single-trial coupling of EEG and fMRI reveals the involvement of early anterior cingulate cortex activation in effortful decision making. Neuroimage 42, 158-168.

Mullette-Gillman, O. A., Detwiler, J. M., Winecoff, A., Dobbins, I., and Huettel, S. A. (2011). Infrequent, task-irrelevant monetary gains and losses engage dorsolateral and ventrolateral prefrontal cortex. Brain Res. 1395, 53-61.

Newman-Norlund, R. D., Ganesh, S., van Schie, H. T., de Bruijn, E. R., and Bekkering, H. (2009). Selfidentification and empathy modulate error-related brain activity during the observation of penalty shots between friend and foe. Soc. Cogn. Affect. Neurosci. 4, 10-22.

Platt, M. L., and Glimcher, P. W. (1999). Neural correlates of decision variables in parietal cortex. Nature 400, 233-238.

Rigoni, D., Polezzi, D., Rumiati, R., Guarino, R., and Sartori, G. (2010). When people matter more than money: An ERPs study. Brain Res. Bull. 81, 445-452.

San Martin, R., Manes, F., Hurtado, E., Isla, P., and Ibanez, A. (2010). Size and probability of rewards modulate the feedback error-related negativity associated with wins but not losses in a monetarily rewarded gambling task. Neuroimage 51, 1194-1204.

Sanfey, A. G., Rilling, J. K., Aronson, J. A., Nystrom, L. E., and Cohen, J. D. (2003). The neural basis of economic decision-making in the Ultimatum Game. Science 300, 1755-1758.

Shackman, A. J., Salomons, T. V., Slagter, H. A., Fox, A. S., Winter, J. J., and Davidson, R. J. (2011). The integration of negative affect, pain and cognitive control in the cingulate cortex. Nat. Rev. Neurosci. $12,154-167$.

Singer, T., Seymour, B., O’Doherty, J., Kaube, H., Dolan, R. J., and Frith, C. D. (2004). Empathy for pain involves the affective but not sensory components of pain. Science 303, 1157-1162.

Singer, T., Seymour, B., O’Doherty, J. P., Stephan, K. E., Dolan, R. J., and Frith, C. D. (2006). Empathic neural responses are modulated by the perceived fairness of others. Nature 439, 466-469.
Stemmer, B., Segalowitz, S. J., Witzke, W., and Schonle, P. W. (2004). Error detection in patients with lesions to the medial prefrontal cortex: an ERP study. Neuropsychologia, 42, 118-130.

van Veen, V., and Carter, C. S. (2002). The anterior cingulate as a conflict monitor: fMRI and ERP studies. Physiol. Behav. 77, 477-482.

van Veen, V., Cohen, J. D., Botvinick, M. M., Stenger, V. A., and Carter, C. S. (2001). Anterior cingulate cortex, conflict monitoring, and levels of processing. Neuroimage, 14 1302-1308.

Westendorff, S., Klaes, C., and Gail, A. (2010). The cortical timeline for deciding on reach motor goals. J. Neurosci. 30, 5426-5436.

Received: 01 April 2013; accepted: 13 April 2013; published online: 08 May 2013.

Citation: Lavin C, Melis C, Mikulan E, Gelormini C, Huepe D and Ibañez A (2013) The anterior cingulate cortex: an integrative hub for human socially-driven interactions. Front. Neurosci. 7:64. doi: 10.3389/fnins. 2013.00064

This article was submitted to Frontiers in Decision Neuroscience, a specialty of Frontiers in Neuroscience. Copyright () 2013 Lavin, Melis, Mikulan, Gelormini, Huepe and Ibañez. This is an open-access article distributed under the terms of the Creative Commons Attribution License, which permits use, distribution and reproduction in other forums, provided the original authors and source are credited and subject to any copyright notices concerning any third-party graphics etc. 